\title{
Avoiding Rice-Based Cadmium and Inorganic Arsenic in Infant Diets Through Selection of Products Low in Concentration of These Contaminants
}

\author{
Zhengyu Shi $^{1} \cdot$ Manus Carey $^{1} \cdot$ Emily Davidson $^{1} \cdot$ Caroline Meharg $^{1} \cdot$ Andrew A. Meharg $^{1}$
}

Received: 21 February 2020 / Revised: 3 August 2020 / Accepted: 11 August 2020 / Published online: 19 August 2020

(c) The Author(s) 2020

\begin{abstract}
Cadmium in the diet is of concern as it is a renal toxicant and a carcinogen, with a half-life in the body measured in decades. Inorganic arsenic is a chronic carcinogen. For many subpopulations, rice and rice products may be the dominate source of cadmium and inorganic arsenic. In particular, rice porridge, cereal and cake are widely used to feed infants (children $<4.5$ years old). In the EU standards for cadmium infant foods in general has been set at $40 \mu \mathrm{g} / \mathrm{kg}$ w.wt., and for inorganic arsenic in rice-based infant foods the standard is $100 \mu \mathrm{g} / \mathrm{kg}$ w.wt.. Here we report cadmium and inorganic arsenic concentrations in rice products marketed for infants, and rice containing products that infants may eat but that are not specifically designated for infants. It was found that while rice-based infant foods conformed to the standards, their non-infant food (generic) analogues did not. Non-infant rice crackers and puffed rice cereals, in particular, had concentrations above these standards for both cadmium and inorganic arsenic. Polished pure rice grain purchased in the UK, but sourced from different countries, was also problematic. Basmati, Italian, Spanish and Thai rice, either exceeded one or the other of the cadmium and inorganic arsenic safety thresholds for infants, or both. Egyptian rice grain was particularly low for both toxins. Therefore, if those responsible for infants want to lower exposure to cadmium and inorganic arsenic, they should stick to foods specifically labeled for infants, or carefully source low cadmium and inorganic arsenic rice-based products that are not specifically labeled as being for infant consumption, or minimize exposure to rice-based foods.
\end{abstract}

Keywords Arsenic $\cdot$ Cadmium $\cdot$ Exposure $\cdot$ Infants $\cdot$ Rice

\section{Introduction}

Human exposure to the carcinogens cadmium and inorganic arsenic, in non-smokers, is primarily through diet (EFSA 2009, 2012; BrF 2018). In particular, rice, the grain staple of half-the-world, tends to be elevated in these toxicants (EFSA 2009, 2012; BrF 2018). For subsistence, rice diets elevated exposure to both cadmium (Meharg et al. 2013; Pastorelli et al. 2018) and inorganic arsenic (Meharg et al. 2009) has given rise to international concern. Globally, most problematic is the exposure of infants to cadmium and inorganic arsenic as they are particularly susceptible to these elements: elevated early life exposure to cadmium

Andrew A. Meharg

aa.meharg@qub.ac.uk

1 Institute for Global Food Security, Queen's University Belfast, Belfast, Ireland and inorganic arsenic are thought to lead to poorer lifetime health outcomes (Carey et al. 2018; Gardener et al. 2019; Ljung et al. 2011; Meharg et al. 2008a, b). Unfortunately, rice is widely fed to infants as it is gluten free, and is often used for weaning (Meharg et al. 2008a, b). Exacerbating exposure to children is the fact that infants consume circa. 3 times more food on a bodyweight basis than adults (EFSA 2009).

Standards have been set in the EU in recognition of the fact that cadmium (European Commission 2006) and inorganic arsenic are problematic in the food-chain (European Commission 2015). Cadmium standards are set for a wide range of food items (European Commission 2006). Of relevance to rice is the fact that maximum concentrations allowed in polished (white) rice grain for cadmium and inorganic arsenic are both $200 \mu \mathrm{g} / \mathrm{kg}$ w.wt. (European Commission 2006, 2015). Infant standards for cadmium (European Commission 2006) and inorganic arsenic (European Commission 2015) have been set lower, at 40 and $100 \mu \mathrm{g} / \mathrm{kg}$ 
w.wt., respectively. However, the inorganic arsenic standard is set on the rice used in formulation, regardless of final concentration, and cadmium is set on absolute concentrations in the product.

As products not specifically labeled as being for infant consumption are fed to infants, there is a gap in the legislation. If parents want to feed children non-infant rice-based foods low in inorganic arsenic and cadmium, advice needs to be given as to what food items are suitable. Knowledge of what potential products are high or low in these toxicants is complicated by the fact that the geographic origin of rice effects both cadmium (Meharg et al. 2013; Shi et al. 2019) and inorganic arsenic (Meharg et al. 2009; Carey et al. 2020) content. Here we report cadmium inorganic arsenic concentrations in rice-based products available on the UK market, examining in particular in how non-infant food relates to that for infants, including rice grain by geographic origin, so that informed choices can be made by those responsible for the diets of children.

\section{Materials and methods}

Rice containing baby products were sampled in 2018 from supermarkets in Northern Ireland to reflect consumer choice. Inorganic arsenic, but not cadmium, was previously reported in these samples (Carey et al. 2018). Survey was systematic in that 3 stores of 6 major retailers (ASDA, Boots, Holland and Barrett, Marks and Spencer, Sainsbury's, Tesco) were visited. All rice-based baby foods, crackers and cereals available at the time of survey in each store were sampled. These included baby rice, rice cereal and rice cake. Details of brand, purchase date, store details, ingredients, and country of origin were recorded and reported in Carey et al. (2018). Note that while sampling took place in Northern Ireland, the source of the rice, brands and distributers are international, and commonplace throughout the UK and EU.

Additionally, polished rice grain were sampled. They were obtained from supermarkets, health food shops and specialty shops in Northern Ireland, with the same sampling strategy as for baby food products. Samples were collected during 2013-2018. Wholegrain is less common and also is not normally fed to young infants and is, therefore, excluded. Grains represented 6-regions, 5 commonly available: basmati (from India \& Pakistan), Spanish, Italian, Thai and the USA. Specialty Egyptian rice was purchased from Halal shops. The polished rice rain data were abstracted from a wider global survey of inorganic arsenic and cadmium in rice reported by Carey et al. (2020) and Shi et al. (2019), respectively, where sampling strategies and experimental design are outlined in full. Sampling frequencies are shown in relevant figures where individual data points are plotted. While the grain survey was opportunistic, it follows the pattern used in similar surveys (Shi et al. 2019). As long as the surveys are interpreted with suitable caution, they provide valuable information, as discussed by Shi et al. (2019).

The samples were dried in a Christ LD freeze dryer, powdered on a rotary ball mill (Retch PM 100 planetary ball mill) using a zirconium oxide-lined grinding chamber and $20 \mathrm{~mm}$ zirconium oxide — plated marbles. Powdered samples were then weighed, $100 \mathrm{mg}$, accurately, using discovery OHAUS digital weighing scales into labeled $50 \mathrm{ml}$ polypropylene (pp) centrifuge tubes (VWR, D\&H and similar). A rice flour certified reference material (CRM), NIST 2018, was also used for each analysis batch, with a batch consisting of 40 samples, and each batch also included an analytical blank.

For cadmium analysis, to each centrifuge tube $2 \mathrm{mls}$ of BDH Prolabo Aristar 69\% nitric acid was added, including the blanks. Tubes were vortexed briefly and left overnight to soak. Following this period, 2mls of BDH Prolabo Analar Normapur $30 \%$ hydrogen peroxide was added to each centrifuge tube via pipette. Tubes were then left open for $15 \mathrm{~min}$ to outgas. Tubes were then placed into the carrousel of a CEM Mars $61800 \mathrm{~W}$ microwave digestor, and the appropriate digestion program selected. The microwave program heated the samples up to $95{ }^{\circ} \mathrm{C}$ gradually through a 3 -stage process over a period of $35 \mathrm{~min}$, then digested the samples at $95{ }^{\circ} \mathrm{C}$ for $30 \mathrm{~min}$. After cooling, a rhodium internal standard (Fluka Analytical) was added, to give a final concentration of $10 \mu \mathrm{g} / \mathrm{l}$, to each sample, and the tubes were made up to their final weights $(\sim 30 \mathrm{~g})$ with deionized water, with precise weights recorded. Multi-Element 2 (SPEX CLMS-2 MultiElement Solution 2, matrix: $5 \% \mathrm{HNO}_{3}$ ) and Multi-Element 4 (SPEX CLMS-4 Multi-Element Solution 4, matrix: water/ Tr-HF) were used to make up all standards in a range of $0-100 \mu \mathrm{g} / \mathrm{l}$. The standard tubes were then made up to final weight $(50 \mathrm{~g})$ with $1 \% \mathrm{HNO}_{3}$. For analysis, $10 \mathrm{ml}$ from the final digestate was poured into $15 \mathrm{ml}$ polypropylene tubes (VWR) and placed into the auto sampler rack (Cetak ASX520 Auto Sampler) in a predetermined random run order.

For arsenic speciation, $10 \mathrm{ml}$ of $1 \%$ conc. Aristar nitric acid was added to the $\sim 0.1 \mathrm{~g}$ of powdered rice and allowed to sit overnight. Samples were then microwaved for $30 \mathrm{~min}$ at $95^{\circ} \mathrm{C}$ using a 3 -stage heating program: to $55^{\circ} \mathrm{C}$ in $5 \mathrm{~min}$ held for $10 \mathrm{~min}$., to $75^{\circ} \mathrm{C}$ in $5 \mathrm{~min}$, held for $10 \mathrm{~min}$ to $95^{\circ} \mathrm{C}$ in $5 \mathrm{~min}$, held for $30 \mathrm{~min}$. On cooling the digestate was diluted to $10 \mathrm{ml}$ with deionized distilled water and then centrifuged for $15 \mathrm{~min}$ at $4500 \mathrm{rpm}$ for. To a $1 \mathrm{ml}$ aliquot in a $2 \mathrm{ml}$ polypropylene vial $10 \mu \mathrm{l}$ of analytical grade $\mathrm{H}_{2} \mathrm{O}_{2}$ was added, converting any arsenite to arsenate, facilitating chromatographic detection.

Shi et al. (2020) outlines the cadmium analytical protocols used here. Summarizing, for cadmium quantification samples was analyzed by ICP-MS (Thermo Scientific iCap Q ICP-MS), interfaced with an auto-sampler. The 
ICP-MS operating conditions were: forward RF power$1550 \mathrm{~W}$; nebulizer gas flow- 1 1/min, nebulizer sample flow rate- $\sim 0.35 \mathrm{ml} / \mathrm{min}$. Helium was used as a collision gas at a flow rate of $5 \mathrm{ml} / \mathrm{min}$. Five cadmium standards were made up including one blank, all in $1 \% \mathrm{HNO}_{3}$. Cadmium recovery was, mean \pm SE, $105 \pm 3.2 \%$. The certified concentration of NIST rice flour CRM was $24 \mu \mathrm{g} / \mathrm{kg}$ d.wt. The limit of detection (LoD) for cadmium was $0.5 \mu \mathrm{g} / \mathrm{kg}$ d.wt. for infant foods, but at $9.8 \mu \mathrm{g} / \mathrm{kg}$ d.wt. for rice grain.

For inorganic arsenic quantification analytical details are given in Carey et al. (2018, 2020). Summarizing, sample solutions were analyzed using a Thermo Scientific IC5000 Ion Chromatography (IC) system fitted with a Thermo AS7, $2 \times 250 \mathrm{~mm}$ column (and a Thermo AG7, $2 \times 50 \mathrm{~mm}$ guard column), using a gradient mobile phase ( $20 \mathrm{mM}$ to $200 \mathrm{mM}$ ammonium carbonate linearly over 15 min., using a flow rate of $0.3 \mathrm{ml} / \mathrm{min}$ ), interfaced with a Thermo ICAP Q ICPMS that monitored $\mathrm{m} / \mathrm{z}^{+} 75$, using helium gas in collision cell mode. Calibration was quantified conducted using a dimethylarsinic acid (DMA) calibration series, and compounds identified through the use of authentic arsenobetaine, arsenate, DMA and monomethylarsonic (MMA) standards. Recovery of the NIST rice flour CRM for inorganic arsenic $(n-76)$ was $99 \pm 1.1 \%$, with a limit of detection of $3 \mu \mathrm{g} /$ kg d.wt..

For infant foods and their generic equivalents, the means of the 3-replicates were obtained. Subsequently, all intercomparisons, between product type and between regions, where appropriate, were conducted using non-parametric tests as the cadmium and arsenic data were not normally distributed using GraphPad Prism for Mac, v. 8. If a sample was below LoD, half-LoD was used in statistical analysis.

Rice grain is normally dried to $12 \%$ for storage (University of Arkansas, 2020), and this conversion factor can be used to approximate wet weights from dry weights if required for grains. This $\sim 12 \%$ moisture lost on drying in effect means that d.wts. need to be multiplied by 1.12 to convert to w.wt., and this should be born in mind when interpreting data.

\section{Results}

The cadmium and inorganic arsenic concentrations in ricebased infant foods and their non-infant food analogues, in relationship to the EU regulations pertaining to infant foods, are shown in Fig. 1. For cadmium, all infant foods were below the EU standard for processed infant foods of $\sim 44.8 \mu \mathrm{g} / \mathrm{kg}$ d.wt., which equates to $40 \mu \mathrm{g} / \mathrm{kg}$ w.wt.. Indeed, all but 4 samples were below $20 \mu \mathrm{g} / \mathrm{kg}$ d.wt.. Mixed cereal cakes had the highest median at $12.8 \mu \mathrm{g} / \mathrm{kg}$ d.wt., and the lowest was mixed grain porridge at $5.1 \mu \mathrm{g} / \mathrm{kg} \mathrm{d}$.wt. These infant products significantly differed $(P=0.019)$. Not
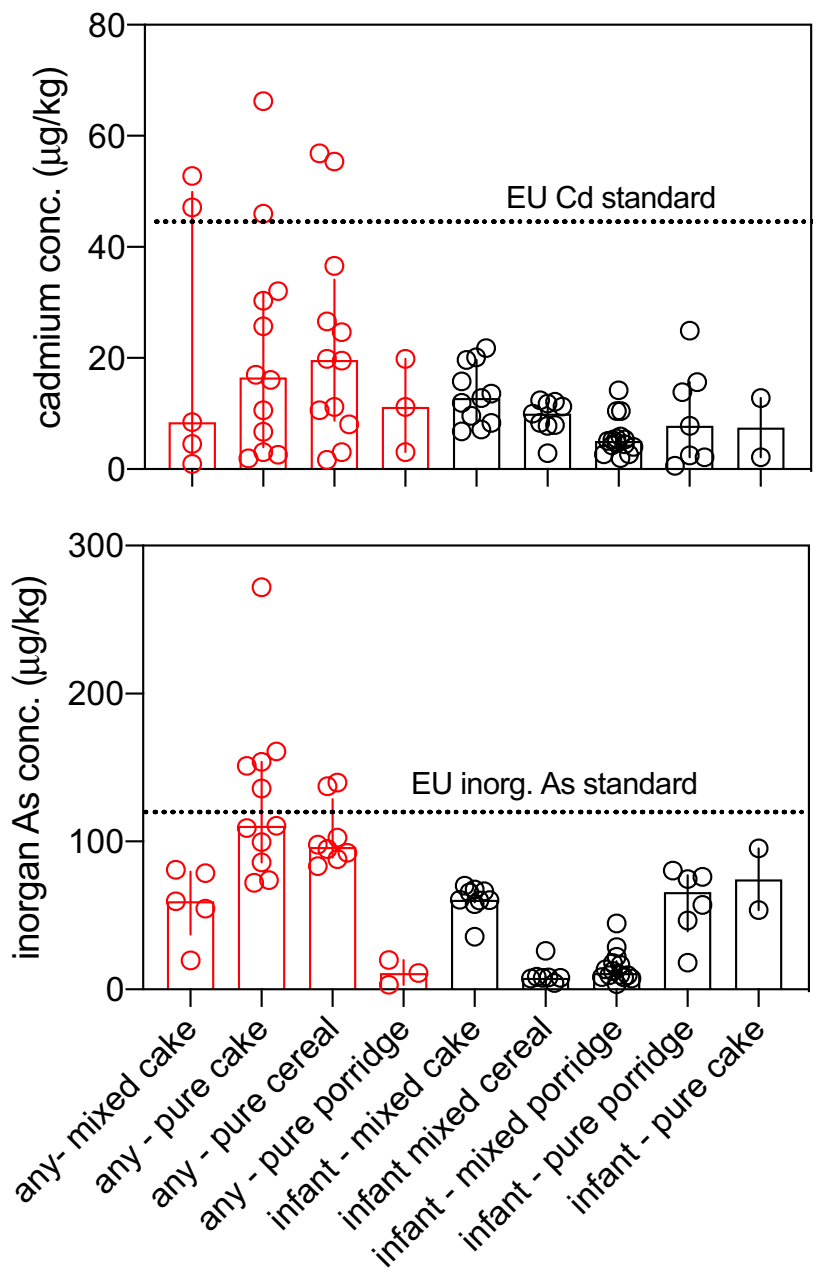

Fig. 1 Median concentrations of cadmium and inorganic arsenic in baby food products. Each point is the average of 3-replicates. Error bars give the 25th and 75th percentile. The dashed lines are for the EU standards for cadmium in infant foods $(\sim 44.8 \mu \mathrm{g} / \mathrm{kg} \mathrm{d.wt}$. $)$ and the proxy-standard of for inorganic arsenic in infant foods $(\sim 112 \mu \mathrm{g} /$ kg d.wt.)

labeled for infants rice-based foods, in contrast, had 6 out of 44 samples exceeding $\sim 44.8 \mu \mathrm{g} / \mathrm{kg}$ d.wt. cadmium, 2 of each from mixed cereal cakes, pure rice cakes and pure rice breakfast cereals, with those exceeding the standard ranging from 46.0 to $66.2 \mu \mathrm{g} / \mathrm{kg}$ d.wt.. For cadmium there was no significant difference $(P>0.05)$ between non-infant products, and for all products.

For inorganic arsenic a proxy standard of $100 \mu \mathrm{g} / \mathrm{kg}$ w.wt., equating to $\sim 112 \mu \mathrm{g} / \mathrm{kg} \mathrm{d}$.wt., was used to compare results to EU guidelines. This standard is denoted as "proxy" as the EU inorganic arsenic standard is set on raw material grain used to produce the products (European Commission 2015). All infant foods were below the $\sim 112 \mu \mathrm{g} / \mathrm{kg}$ d.wt. proxy standard (Fig. 1). Non-infant products had some samples above the proxy standard, with pure rice cakes and pure rice cereals both having medians above $\sim 112 \mu \mathrm{g} / \mathrm{kg}$ d.wt. 
All infant foods were below the EU threshold (Fig. 1), but mixed grain infant cereals $(7.8 \mu \mathrm{g} / \mathrm{kg}$ d.wt.) and porridges $(11.9 \mu \mathrm{g} / \mathrm{kg}$ d.wt.) had medians considerably below mixed cake $(60.6 \mu \mathrm{g} / \mathrm{kg}$ d.wt.), and pure porridge $(65.9 \mu \mathrm{g} / \mathrm{kg}$ d.wt.) and cake $(74.4 \mu \mathrm{g} / \mathrm{kg}$ d.wt.). There were highly significant differences $(P<0.0001)$ when comparing all products, and within infant products. Differences between non-infant products were significant with $P=0.014$.

Plotting individual products cadmium and inorganic arsenic non-infant pure rice cakes had 2 products that exceeded both infant (proxy) inorganic arsenic and cadmium standards (Fig. 2). Pure rice cereals borders on exceedance of both standards for 3 products, and two mixed grain rice cakes are in a similar position. Linear regression of inorganic arsenic plotted against cadmium for the entire data set was significant $(\mathrm{P}<0.0001)$. The slope, origin set to zero, was 0.031 , and thus inorganic concentrations are $\sim$ threefold higher than cadmium in rice-based baby food products.

When considering pure polished rice grains the median cadmium content of basmati rice was $33.4 \mu \mathrm{g} / \mathrm{kg}$ d.wt., with a 75 th percentile of $55.4 \mu \mathrm{g} / \mathrm{kg}$ d.wt.. This was above the infant rice standard of $\sim 44.8 \mu \mathrm{g} / \mathrm{kg}$ d.wt. (Fig. 3). Italian rice had a median of $40.1 \mu \mathrm{g} / \mathrm{kg}$ d.wt., with a 75 th percentile of $60.2 \mu \mathrm{g} / \mathrm{kg}$ d.wt.. The maximum for Italy was $117 \mu \mathrm{g} / \mathrm{kg}$ d.wt. Thai rice had a 75 th percentile above the EU estimated d.wt. threshold, at $\sim 44.8 \mu \mathrm{g} / \mathrm{kg}$ d.wt.. Spain had a low median and 75th percentile, but the maximum value was above the EU threshold. Egyptian and Spanish rice had medians at the half-LoD $(4.9 \mu \mathrm{g} / \mathrm{kg}$ d.wt. $)$, and the USA double this, though with a low sample size $(n=3)$. The medians between countries differed significantly when a Kruskal-Wallis analysis was performed on the data $(P<0.0001)$.

Italian rice had the highest median inorganic arsenic at $106 \mu \mathrm{g} / \mathrm{kg}$ d.wt., with the d.wt. corrected standard being $\sim 112 \mu \mathrm{g} / \mathrm{kg}$ d.wt. (Fig. 3). The 75 th percentile was $126 \mu \mathrm{g} / \mathrm{kg}$ d.wt., and the maximum $244 \mu \mathrm{g} / \mathrm{kg}$ d.wt.. Basmati $(28.9 \mu \mathrm{g} / \mathrm{kg}$ d.wt.) and Egyptian $(30.2 \mu \mathrm{g} / \mathrm{kg}$ d.wt. $)$ had the lowest medians, with maximums well below EU d.wt.
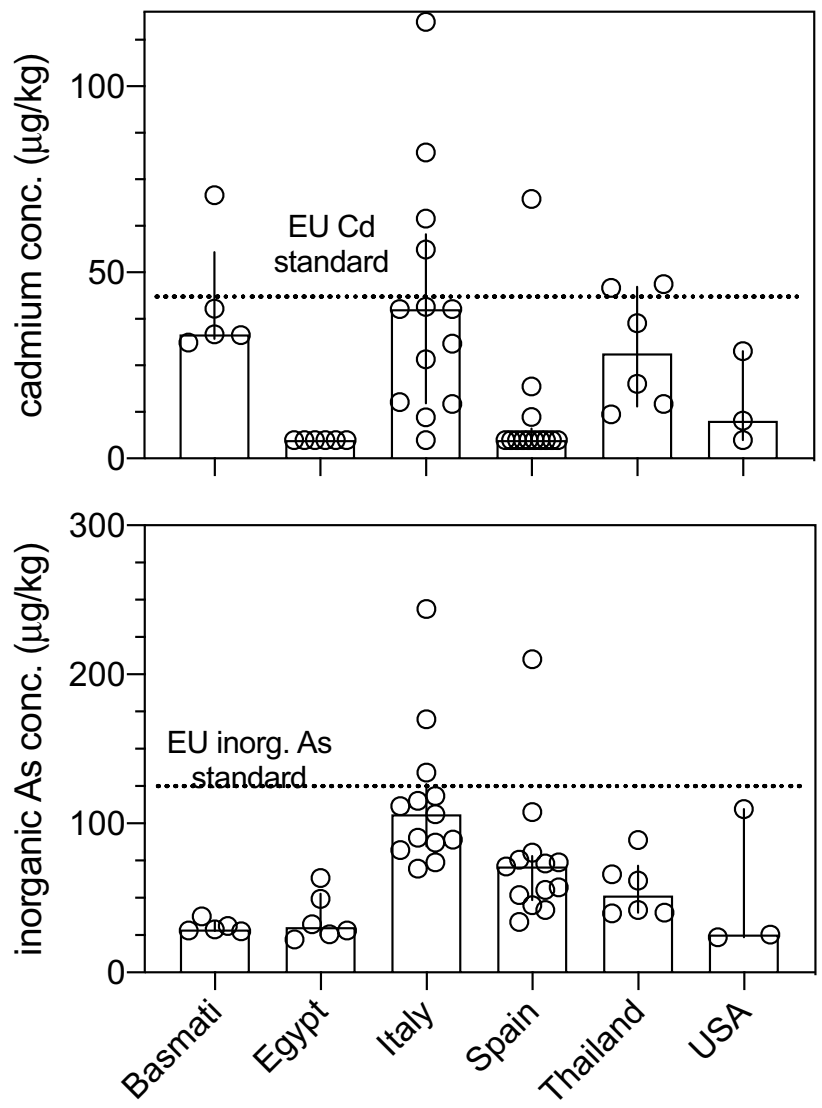

Fig. 3 Median concentrations of cadmium and inorganic arsenic UK purchased rice by country of origin. Error bars give the 25th and 75th percentile. The dashed lines are for the EU standards for cadmium in infant foods $(\sim 44 \mu \mathrm{g} / \mathrm{kg} \mathrm{d}$.wt.) and the proxy-standard of for inorganic arsenic in infant foods $(\sim 112 \mu \mathrm{g} / \mathrm{kg} \mathrm{d}$.wt.)

approximated threshold of $\sim 112 \mu \mathrm{g} / \mathrm{kg}$ d.wt.. Thailand and USA also had maximums below the EU threshold. Medians were highly significantly different between regions $(\mathrm{P}<0.0001)$. The maximum Spanish sample was $210 \mu \mathrm{g} /$ $\mathrm{kg}$ d.wt., but median and 75th percentile were well below the $\sim 112 \mu \mathrm{g} / \mathrm{kg}$ w.wt. standard.
Fig. 2 Plot of cadmium versus inorganic arsenic for infant food products. Each point is the average of 3-replicatse. Error bars give the 25 th and 75 th percentile. The dashed lines are for the EU standards for cadmium in infant foods $(\sim 44.8 \mu \mathrm{g} / \mathrm{kg}$ d.wt.) and the proxy-standard of for inorganic arsenic in infant foods $(\sim 112 \mu \mathrm{g} / \mathrm{kg}$ d.wt. $)$. A regression through the whole dataset is shown by the dotted grey line

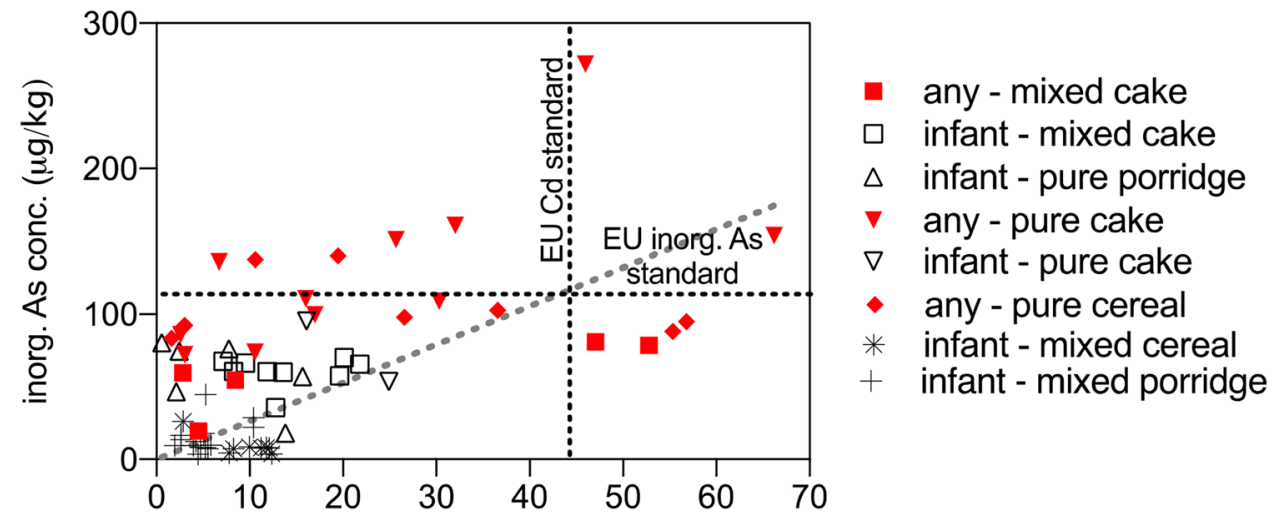


Considering cadmium and inorganic arsenic together, it is only Egyptian rice that is low in both toxins. Italian rice was problematic for both toxicants, while Spain, Thailand and USA were intermediate. When inorganic arsenic is plotted against cadmium concentrations (Fig. 4), Italian rice is the only region where medians exceed both d.wt. corrected limits, while Egyptian rice is the only one to exceed none. Linear regression of the entire dataset, with origin set to zero, was significant $(P<0.0001)$. The slope of inorganic arsenic verses cadmium content was 0.27 , similar to the corresponding slope for the similar plot for processed infant foods (Fig. 2)..

\section{Discussion}

From the findings reported here, rice products not labeled as being specifically for infant consumption are problematic with respect to their cadmium and inorganic arsenic contents if they are to be used as infant foods. This is because rice products not specifically labeled for infant consumption routinely exceed the standards for either cadmium or proxy inorganic arsenic set for infant foods, or both, in a non-predictable manner. The only exception to this statement is Egyptian rice, which is consistently low in both inorganic arsenic and cadmium. Puffed rice cereals are often marketed at children, with cartoon characters often on packaging. Puffed rice has a higher standard $(300 \mu \mathrm{g} / \mathrm{kg} \mathrm{w}$.wt.) for inorganic arsenic than polished rice or rice destined for infant foods (European Commission 2015). Many rice-based products are formulated using puffed rice. It is confusing to set much lower standards for infant foods if infants are also exposed to generic foods that have higher standards? Rice milk tends to be elevated in inorganic arsenic (Meharg et al. 2008a, b). The UK
Food Standards Agency (FSA) has asked that rice milk cartons have a warning printed on them that infants should not consume this product (FSA 2018). This UK rice milk arsenic approach shows that advice can be given clearly around toxicants to those providing foods for infants (FSA 2018). This labeing approach needs to be widened to all rice-based products, such as to puffed rice and polished rice grain, for both inorganic arsenic and for cadmium, if infants may routinely consume them.

The rice grain most suitable for infant consumption with respect to low cadmium and inorganic arsenic, available to European markets, is Egyptian. However, Egyptian rice is a specialty product, and on a global scale is relatively limited in availability, accounting for $0.8 \%$ of the global production, with only $\sim 1 \%$ exported (FAO 2018). We have also identified that East African, Malawian and Tanzanian, rice is lower than Egyptian in both inorganic arsenic (Carey et al. 2020) and cadmium (Shi et al. 2019). Again, production from these two regions is limited on a global scale, accounting for $\sim 0.5 \%$ of global production, with little export (FAO 2018). Also, there are agronomic constraints to expanding both East African (Meertens 2003) and Egyptian (Fan et al. 1997) rice production.

The lack of wide availability of low-arsenic and cadmium rice, and of labeling so that such products can be identified, then poses the question as to what can careers do to reduce infant exposure to these chemicals? One obvious solution is to avoid rice. Rice is preferred for a number of diets compared to gluten containing grains such as wheat and barley. Also, wheat, barley and oats can be high in cadmium (BfR 2018; Clemens et al. 2013; John et al. 1972).

Gluten free grains and grains are obvious alternatives to rice, such as maize, amaranth, quinoa, chia etc. This has been realized by infant food manufacturers producing
Fig. 4 Plot of cadmium and inorganic arsenic UK purchased rice by country of origin. Error bars give the 25 th and 75 th percentile. The dashed lines are for the EU standards for cadmium in infant foods $(\sim 44.8 \mu \mathrm{g} / \mathrm{kg}$ d.wt.) and the proxy-standard of for inorganic arsenic in infant foods $(\sim 112 \mu \mathrm{g} / \mathrm{kg}$ d.wt.). A regression through the whole dataset is shown by the dotted grey line

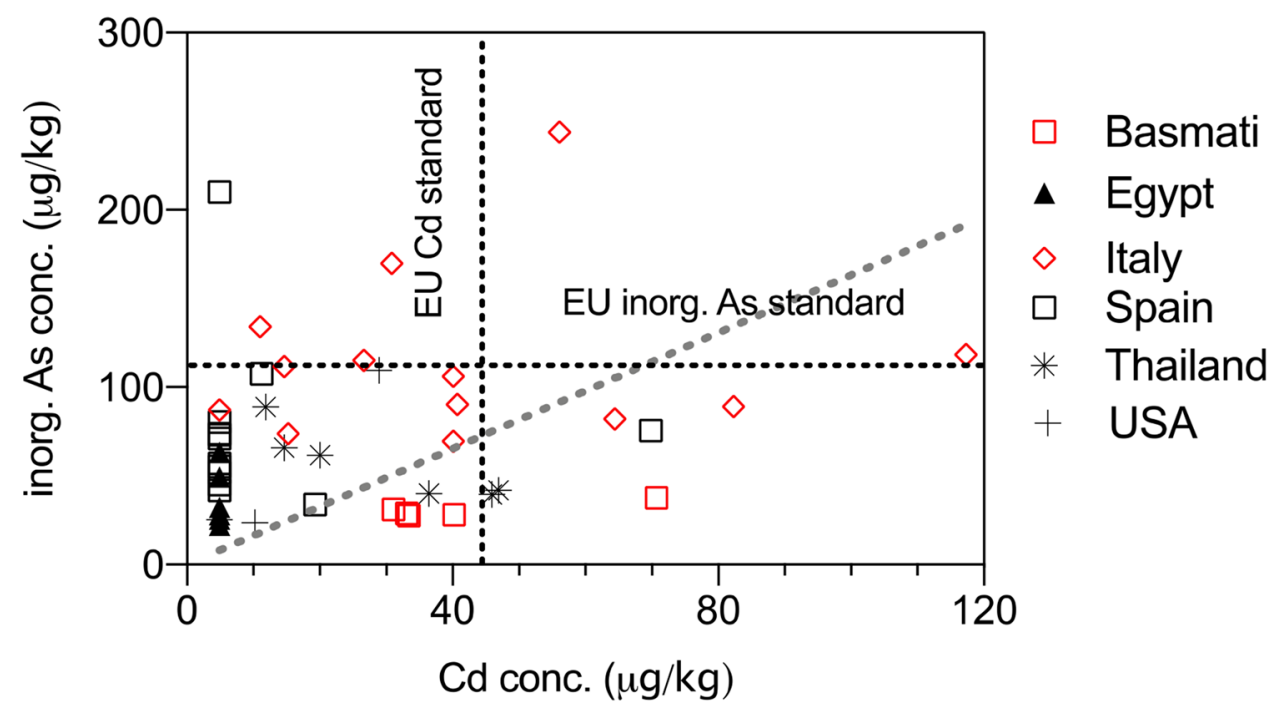


products were rice is mixed with other grains for low inorganic arsenic (Carey et al. 2018). We show here that this is also effective for cadmium.

If polished rice grain is to be used, simple cooking techniques, presoaking rice and then cooking a large water:rice ratio, can be used to lower inorganic arsenic content, by 70-80\% (Carey et al. 2015; Raab et al. 2009). Cadmium is not readily removed, so selection of low cadmium rice becomes particularly important. Egyptian and Spanish rice are relatively low in cadmium, as reported here. Wholegrain rice should be avoided if the aim is to minimize cadmium and inorganic arsenic in the diets of children as wholegrain has $\sim$ double the inorganic arsenic content of polished rice (Meharg et al. 2009).

Concluding, in the absence of clear and comprehensive standard setting and governmental advice it is possible for those responsible for the diets of infants to simultaneously lower dietary exposure to inorganic arsenic and cadmium. This can be done by: choosing foods that are specifically designated only for infants (at least in the EU), avoidance of rice-based products, use foods specifically reduced in rice content, sourcing of rice grain that is low in both cadmium and inorganic arsenic, and cooking out inorganic arsenic out of low cadmium rice.

Open Access This article is licensed under a Creative Commons Attribution 4.0 International License, which permits use, sharing, adaptation, distribution and reproduction in any medium or format, as long as you give appropriate credit to the original author(s) and the source, provide a link to the Creative Commons licence, and indicate if changes were made. The images or other third party material in this article are included in the article's Creative Commons licence, unless indicated otherwise in a credit line to the material. If material is not included in the article's Creative Commons licence and your intended use is not permitted by statutory regulation or exceeds the permitted use, you will need to obtain permission directly from the copyright holder. To view a copy of this licence, visit http://creativecommons.org/licenses/by/4.0/.

\section{References}

BfR Opinion No. 026/2018 (2018) EU maximum levels for cadmium in food for infants and young children sufficient: exposure to lead should fundamentally be reduced to the achievable minimum. https://doi.org/10.17590/2018120-132313-0

Carey M, Donaldson E, Signes-Pastor AJ, Meharg AA (2018) Dilution of rice with other gluten free grains to lower inorganic arsenic in foods for young children in response to European Union regulations. PLoS ONE 13:e01947000

Carey M, Meharg C, Williams P, Marwa E, Jiujin X, Gomes Farias J, De Silva PMCS, Signes-Pastor A, Lu Y, Nicoloso FT, Savage L, Campbell K, Elliott C, Adomako E, Green AJ, Moreno-Jiménez E, Carbonell-Barrachina AA, Triwardhani EA, Pandiangan FI, Haris PI, Lawgali YF, Sommella A, Pigna M, Brabet C, Montet D, Njira K, Watts MJ, Meharg AA (2020) Global sourcing of low-inorganic arsenic rice grain. Expos Health. https://doi. org/10.1007/s12403-019-00330-y
Carey MP, Jiujin X, Gomes Farias J, Meharg AA (2015) Rethinking rice preparation for highly efficient removal of inorganic arsenic using percolating cooking water. PLoS ONE 1:e0131608

Clemens S, Aarts MGM, Thomine S, Verbruggeb N (2013) Plant science: the key to preventing slow cadmium poisoning. Trends Plant Sci 18:92-99

European Commission (2006) regulation No 1881/2006 Setting maximum levels for certain contaminants in foodstuffs. https://eur-lex. europa.eu/legal-content/EN/TXT/?uri=CELEX:02006R1881 $-20150521$

European Commission (2015) regulation No. 2015/1006 Amending Regulation (EC) No 1881/2006 as regards maximum levels of inorganic arsenic in foodstuffs. https://op.europa.eu/en/publicatio n-detail/-/publication/4ea62ae9-1bc8-11e5-a342-01aa75ed71 a1 arsenicrice

EFSA, European Food Safety Authority (2009) Panel on Contaminants in the Food Chain (CONTAM)/ Scientific opinion on arsenic in food. EFSA J 7:1351

EFSA, European Food Safety Authority (2012) Cadmium dietary exposure in the European population. EFSA J 10:2551

Fab SG, Wailes EJ, Young KB (1997) Policy reforms and technological changes in Egyptian rice production: a frontier production function approach. J Afr Econ 6:391-411

FAO (2018) Rice market monitor. https://www.fao.org/3/I9243EN/ i9243en.pdf

Food Standards Agency (2018) Arsenic in rice. Advice on safe levels of arsenic in rice and rice milk. https://www.food.gov.uk/safety-hygie ne/arsenic-in-rice

Gardener H, Bowen J, Callan SP (2019) Lead and cadmium contamination in a large sample of United States infant formulas and baby foods. Sci Total Environ 651:822-827

John MK, Chuah HH, VanLaerhoven CJ (1972) Cadmium contamination of soil and its uptake by oats. Environ Sci Technol 6:555-557

Ljung K, Palm B, Grander M, Vahter M (2011) High concentrations of essential and toxic elements in infant formulae and infant foodsa matter of concern. Food Chem 127:943-951

Meerten HCC (2003) The prospects for integrated nutrient management for sustainable rainfed lowland rice production in Sukumaland, Tanzania. Nutr Cycl Agroecos 65:163-171

Meharg AA, Deacon C, Campbell RCJ, Carey A-M, Williams PN, Feldmann J, Raab A (2008) Inorganic arsenic levels in rice milk exceed EU and US drinking water standards. J Environ Monitor 10:428-431

Meharg AA, Sun G, Williams PN, Adamako E, Deacon C, Zhu YG, Feldmann J, Raab A (2008) Inorganic arsenic levels in baby rice are of concern. Environ Pol 152:746-749

Meharg AA, Norton G, Deacon C, Williams P, Adomako EE, Price A, Zhu YG, Li G, Zhao FJ, McGrath S, Villada A, Sommella A, De Silva PM, Brammer H, Dasgupta T, Islam R (2013) Variation in rice cadmium related to human exposure. Environ Sci Technol 47:5613-5618

Meharg AA, Williams PN, Adomako E, Lawgali YY, Deaon C, Villada A, Cambell RCJ, Sun G, Zhu YG, Feldmann J, Raab A, Zhao FJ, Islam R, Hossain S, Yanai J (2009) Geographical variation in total and inorganic arsenic content of polished (white) rice. Environ Sci Technol 43:1612-1617

Pastorelli AA, Angeletti R, Binato G, Mariani MB, Cibin V, Morelli S, Ciardullo S, Stacchini P (2018) Exposure to cadmium through Italian rice (Oryza sativa $\mathrm{L}$.): consumption and implications for human health. J Food Comp Anal 69:115-121

Raab A, Baskaran C, Feldmann J, Meharg AA (2009) Cooking rice in a high water to rice ratio reduces inorganic arsenic content. $\mathrm{J}$ Environ Monit 11:41-44

Shi Z, Carey M, Meharg C, Williams P, Signes-Pastor AJ, Triwardhani EA, Pandianga FI, Campbell K, Elliott C, Marwa E, Xia J, Gomes Farias J, Nicoloso FT, De Silva PMCS, Lu Y, Norton G, Adomako 
E, Green AJ, Moreno-Jimenez E, Carbonell-Barrachina ÁA, Haris PI, Lawgali YF, Sommella A, Pigna M, Brabet C, Montet D, Njira K, Watts MJ, Hossain M, Islam MR, Tapia Y, Orport C, Meharg AA (2019) A three-order of magnitude range in grain cadmium un the global supply-chain. Exposure Health. https://doi.org/10.1007/ s12403-020-00349-6

University of Arkansas (2020) On-farm rice drying and storage. https:// www.uaex.edu/farm-ranch/crops-commercial-horticulture/Grain _drying_and_storage/rice_drying_and_storage.aspx
Publisher's Note Springer Nature remains neutral with regard to jurisdictional claims in published maps and institutional affiliations. 